\title{
NGHIÊN CÚU ẢNH HƯởNG CỦA CHẾ Độ ĂN TRƯờNG CHAY TRÊN CHỈ SỐ MỠ CƠ THỂ VÀ MỨC MỠ NỘI TANG
}

Võ Hoàng Lâm ${ }^{l}$, Ngô Thị Minh Thảol, Lê Trọng Hiếu ${ }^{l}$, Nguyêิ㇒n Văn Nhật Thành ${ }^{l}$, Nguyễn Bảo Chi ${ }^{l}$, Huỳnh Lê Thảo Nguyêen ${ }^{1}$, Nguyễn Hải Thủ̉ ${ }^{2}$

1. Sinh viên TrườngĐại học Y Dược, Đại học Huế

DOI: 10.47122/vjde.2020.38.11

\section{ABSTRACT \\ Effects of vegetarian diet on body fat percentage and viceral fat level}

Body fat percentage and visceral fat level was considered to be the anthropometric indices and equivalent to BMI, waist, but there has not been much study on people had vegetarian diet. The objectives are to evaluate the BFP, VFL and to identify the relation of long-time vegetarian, risk factor and BFP, VFL on women had vegetarian diet. Method: 239 females (age 45-55 years) had vegetarian and 239 non-vegetarian women (age 45-55 years) were control group. Result: For vegetarian, there was $82.0 \%$ on the high BFP, while the figure for high VFL was $28.0 \%$. The risk of increase BFP, VFL in vegetarian group compared to non-vegetarian women were 1.60 and 1.55 respectively. There was correlation between long-time vegetarian and BFP $(r=0.437)$, and between long-time vegetarian and VFL $(r=0.625)$.In term of long-time vegetarian, time>8year was related elevating BFP and >20 year was related raising VFL. Conclusion: The risk of increase BFP, VFL in vegetarian group compared to non-vegetarian women were 1.60 and 1.55 respectively. There was correlation between long-time vegetarian and BFP and between long-time vegetarian and VFL.

Keywords: Body fat percentage, visceral fat level, VFL, BFP, long-time vegetarian.

\section{TÓM TẮT}

Tỉ lệ mỡ cơ thể (BFP) và mức mỡ nội tạng (VFL) được xem như những chỉ số nhân trắc tương đương với chỉ số $\mathrm{BMI}$ và vòng bụng trong đánh giá một số yếu tố nguy cơ bệnh lý. Mục tiêu: Nghiên cứu chỉ số BFP, VFL ở phụ nữ ăn chay trường và khảo sát tương quan giữa thời gian ăn chay với chỉ số $\mathrm{BFP}, \mathrm{VFL}$ trên phụ nữ ăn chay trường. Đối tượng và phương pháp: Mô tả cắt ngang ở 239 phụ nữ có chể độ ăn chay trường và 239 phụ nữ không ăn chay. Kết quả: Nhóm ăn chay BFP tăngchiếm 82,0\%, VFL 28,0\%. Nguy cơ tăng $\mathrm{BFP}$, VFL ở nhóm ăn chay trường cao gấp 1,60 và 1,55 lần so với nhóm không ăn chay. Thời gian ăn chay (TGAC) tương quan thuận trung bình với $\mathrm{BFP}(\mathrm{r}=0,437)$; và $\mathrm{TGAC}$ tương quan thuận với VFL $(\mathrm{r}=0.625)$. Tại điểm cắt $\mathrm{TGAC}>8$ năm có nguy cơ tăng $\mathrm{BFP}$, $>20$ năm có nguy cơ tăng VFL. Kết luận: Ở phụ nữ ăn chay trường có nguy cơ tăng BFP, VFL cao gấp 1,60 và 1,55 lần so với nhóm không ăn chay. Thời gian ăn chay tương quan thuận với $B F P$ và $V F L$.

Tù khóa: Chi số mõ cơ thể, mức mõ nội tạng, VFL, BFP, thời gian ăn chay.

Chịu trách nhiệm chính: Nguyễn Hải Thủy

Ngày nhận bài: 03/01/2020

Ngày phản biện khoa học:14/1/2020

Ngày duyệt bài: 27/02/2020

Email:nhthuy52@gmail.com

ĐT: 0903574457

\section{1. ĐặT VẤN ĐỀ}

Béo phì là tình trạng tích lũy quá nhiều và bất thường của lipid trong các tổ chức mỡ. Béo phì đứng hàng đầu trong nhóm "các bệnh của nền văn minh", khi bị béo phì có thể làm gia tăng các bệnh lý tim mạch, bệnh lý chuyển hóa và nội tiết... Béo phì là bệnh thường gặp nhất và có tính chất toàn cầu có liên quan đến chế độ ăn, tỷ lệ bệnh và tần suất bệnh đang gia tăng rất rõ. Hiện nay, Tổ chức Y tế xem thừa cân - béo phì là một nạn dịch toàn cầu[9]. Dựa vào vị trí phân bố, mỡ được chia làm ba loại bao gồm mỡ cơ thể, mỡ nội 
tạng, mỡ dưới da. Mỡ nội tạng được định nghĩa là phần mô mỡ ở bụng và các cơ quan quan trọng xung quanh. Mỡ nội tạng quá cao được coi là nguyên nhân trực tiếp làm tăng lượng mỡ trong máu dẫn đến nguy cơ mắc các bệnh như: cholesterol máu cao, bệnh tim, tiểu đường typ 2[8].

Tích tụ mỡ nội tạng liên quan đến không chỉ cho sự phát triển của nguy cơ tim mạch, mà còn liên quan trực tiếp đến sự phát triển của bệnh tim mạch. Nghiên cứu của Matsuzawa $Y$ và cộng sự vào năm 2012 đã chứng minh rằng béo phì nội tạng có liên quan đến bệnh lý động mạch vành ngay cả ở những người béo phì nhẹ. Tích tụ mỡ nội tạng cũng liên quan đến nhiều bệnh lý nguy hiểm khác như: Rối loạn chức năng tim, hội chứng ngưng thở khi ngủ, hội chứng chuyển hóa... Từ kết quả nghiên cứu, tác giả đã kết luận được sự tích lũy chất béo nội tạng là một nguy cơ chính của bệnh tim mạch cũng như các bệnh lý chuyển hóa[7].

Hiện nay, đã có nhiều nghiên cứu trên thế giới và trong nước chú ý đến tỉ lệ mỡ cơ thể (BFP) và mức mỡ nội tạng (VFL). Mỡ cơ thể và mức mỡ nội tạng được xem như những chỉ số nhân trắc tương đương với chỉ số $\mathrm{BMI}$ và vòng bụng trong đánh giá một số yếu tố nguy cơ, đặc biệt là hội chứng chuyển hóa và tim mạch. Có thể xác định các chỉ số mỡ theo nhiều cách khác nhau như: Phương pháp đo độ dày nếp gấp da bằng thước compa, phương pháp nhân trắc, phương pháp DEXA hấp thụ năng lượng kép... nhưng phương pháp phân tích trở kháng điện sinh học vẫn được sử dụng nhiều nhất bởi độ chính xác cao, giá thành rẻ, dễ sử dụng, không gây hại và có thể lặp lại nhiều lần [8].

Hiện nay, chế độ tiết thực ăn chay có khuynh hướng phổ biến với nhiều lý do trong đó có mục đích phục vụ sức khỏe. Vậy ở những người có chế độ ắn chay lâu năm thì chỉ số tỉ lệ mỡ cơ thể và mức mỡ nội tạng như thế nào. Hiện nay, chưa có nhiều nghiên cứu về chỉ số tỉ lệ mỡ cơ thể và mức mỡ nội tạng ở những người có chế độ ăn chay. Do đó chúng tôi tiến hành nghiên cứu đề tài "Nghiên cứu ảnh hưởng của chế độ ăn chay trường trên chỉ số mõ cơ thể và múc mõ nội tạng” với các mục tiêu:

1. Nghiên cúu chỉ số tỉ lệ mõ cơ thể, mức mõ nội tạng ở phu nũ ăn chay trường.

2. Khảo sát mối tuoong quan giữa thời gian ăn chay với chỉ số mõ co thể, mõ nội tạng trên phụ nũ ăn chay trường.

\section{2. ĐỐI TƯợNG VÀ PHƯƠNG PHÁP NGHIÊN CÚU}

Nghiên cứu thực hiện trên 239 phụ nữ tuổi từ 45-55 có chế độ ắn chay trường, nhóm chứng gồm 239 phụ nữ không ăn chay từ 45 55 tuổi tại Thừa Thiên Huế.

\section{1. Đối tượng}

2.1.1. Tiêu chuẩn chọn: Nhóm nghiên cứu:

- Phụ nữ có chế độ ăn chay trường. Thời gian ăn chay tối thiểu $>1$ năm.

- Tuổi 45 đến 55 tuổi. Đồng ý tham gia nghiên cứu.

Nhóm chứng:

- Phụ nữ có chế độ ăn bình thường. Tuổi 45 đến 55 tuổi. Đồng ý tham gia nghiên cứu.

\subsubsection{Tiêu chuẩn loại trù̀}

Những đối tượng đang có bệnh lý nhiễm khuẩn, phù đang điều trị với thuốc corticoid, thuốc lợi tiểu. Hoạt động thể lực nặng. Đang mang thai. Rối loạn tâm thần.

\subsection{Phương pháp nghiên cứu:}

- Thiết kế nghiên cứu: Nghiên cứu mô tả cắt ngang có đối chứng.

- Thời gian và địa điểm nghiên cứu: Từ tháng 01/2018 - 06/2019 tại các chùa trên địa bàn tỉnh Thừa Thiên Huế.

- Cách chọn mẫu: Tất cả các đối tượng đủ tiêu chuẩn chọn nghiên cứu ở các chùa $n=$ 239. Để đảm bảo tính tin cậy của nghiên cứu đã chọn tỉ lệ nhóm nghiên cứu/nhóm chứng là $1 / 1$. Vậy cỡ mẫu cho nhóm chứng $n=239$. Nhóm chứng chọn theo cách chọn mẫu ngẫu nhiên đơn.

- Các bước tiến hành:

Phưong tiện nghiên cúu: Phiếu điều tra, ống nghe tim phổi, máy đo huyết áp, máy kháng định sinh học Omron loại HBF-362, thước dây.

Tiến hành nghiên cưu: Phỏng vấn đối 
tượng theo phiếu điều tra: Hỏi tiền sử, bệnh sử, đo vòng bụng, đo huyết áp, chiều cao, đo chỉ số tỷ lệ mỡ cơ thể (BFP), đo mức mỡ nội tạng (VFL), khám lâm sàng.

Cách đo các chỉ số BFP, VFL: Nhập dữ liệu tuổi, giới, chiều cao. Khi màn hình hiển thị $0,0 \mathrm{~kg}$, bước hai chân lên hai điện cực đồng thời hai tay nắm vào hai điện cực theo các rãnh dọc theo điện cực. Thời điểm đo: 7- 8 giờ sáng. Tư thế đo: Đầu, lưng, hai đầu gối thẳng, hai tay nắm chặt, cánh tay thẳng tạo góc $90^{\circ}$ với cơ thể, giữ nguyên tư thế đó trong 5 giây. Máy tự động hiển thị các thông số cân nặng, BFP, VFL, BMI. Việc đo hoàn tất, mời đối tượng bước xuống khỏi điện cực, cân tự động tắt nguồn[1].

Đối tượng cần nghỉ ngơi 5-10 phút trước khi đo chỉ số BFP,VFL. Đối tượng trước đó không sử dụng chất kích thích, bia rượu, không uống nhiều nước, không tắm, không sốt hoặc cảm lạnh[1].

Tiêu chí: Ân chay trường: Người ăn chay trường không ăn thực phẩm từ thịt cũng như các sản phẩm từ động vật. Việc ăn chay kéo dài liên tục, không bị xen kẽ với những bữa không ăn chay thì được gọi là ăn chay trường.

Giá trị $\mathrm{BFP}$ ở nữ giới: Bình thường là $<30 \%$ và giá trị VFL theo Hội béo phì Nhật Bản ở nữ giới: Bình thường là 1-9[6].

\subsection{Xử lý số liệu:}

Số liệu nghiên cứu được xử lý và phân tích bằng chương phần mềm Medcalc, Excel 2017 với độ tin cậy tối thiểu $95 \%, \alpha<0,05$.

\section{KẾT QUẢ NGHIÊN CÚU}

Bảng 1. Đặc điểm chung

\begin{tabular}{|c|c|c|c|c|c|c|}
\hline \multicolumn{2}{|c|}{ Tỷ lệ } & $\begin{array}{c}\text { Nhóm ăn } \\
\text { chay } \\
(n=239)\end{array}$ & Tỷ lệ & $\begin{array}{c}\text { Nhóm } \\
\text { không ăn } \\
\text { chay(n=239) }\end{array}$ & Tỷ lệ & $\mathbf{p}$ \\
\hline \multirow[t]{4}{*}{ Địa dư } & Thành phố & 105 & 43,8 & 104 & 43,5 & \multirow{10}{*}{$p>0,05$} \\
\hline & Nông thôn & 100 & 41,5 & 113 & 47,2 & \\
\hline & Miền núi & 21 & 8,9 & 9 & 3,9 & \\
\hline & Miền biển & 13 & 5,6 & 13 & 5,4 & \\
\hline \multirow[t]{2}{*}{ BMI } & $\geq 23 \mathrm{~kg} / \mathrm{m}^{2}$ & 62 & 25,9 & 68 & 28,5 & \\
\hline & $<23 \mathrm{~kg} / \mathrm{m}^{2}$ & 177 & 74,1 & 171 & 71,5 & \\
\hline \multirow[t]{2}{*}{ HA } & $\geq 140 / 90$ & 25 & 10,5 & 46 & 19,3 & \\
\hline & $<140 / 90$ & 214 & 89,5 & 193 & 80,7 & \\
\hline \multirow{2}{*}{$\begin{array}{l}\text { Vòng } \\
\text { bụng }\end{array}$} & $\geq 80 \mathrm{~cm}$ & 147 & 61,5 & 125 & 52,3 & \\
\hline & $<80 \mathrm{~cm}$ & 92 & 38,5 & 114 & 47,7 & \\
\hline
\end{tabular}

Nhóm ăn chay $B M I \geq 23 \mathrm{~kg} / \mathrm{m}^{2}$ là $25,9 \%$ và nhóm không ăn chay $B M I \geq 23 \mathrm{~kg} / \mathrm{m}^{2}$ là $28,5 \%$. Mức huyết áp $<140 / 90$ chiếm $89,5 \%$ nhóm ăn chay và $80,7 \%$ nhóm không ăn chay. Tỷ lệ $\mathrm{VB} \geq 80 \mathrm{~cm}$ chiếm $61,5 \%$ và $52,3 \%$ lần lượt ở nhóm ăn chay nhóm không ăn chay, sự khác biệt không có ý nghĩa thống kê p>0,05.

Bảng 2. Phân bố tỷ lệ mỡ cơ thể

\begin{tabular}{|l|c|c|c|c|c|c|}
\hline \multirow{2}{*}{$\begin{array}{l}\text { Nhóm } \\
\text { đối tượng }\end{array}$} & \multicolumn{2}{c|}{$\begin{array}{c}\text { Bình thường } \\
(\mathbf{2 0}-<\mathbf{3 0 \%})\end{array}$} & $\begin{array}{c}\text { Tăng } \\
(\geq \mathbf{3 0 \%})\end{array}$ & \multicolumn{2}{c|}{ Tổng } \\
\cline { 2 - 7 } & $\mathbf{n}$ & $\mathbf{\%}$ & $\mathbf{n}$ & $\mathbf{\%}$ & $\mathbf{n}$ & \% \\
\hline Nhóm có ăn chay & 43 & 18,0 & 196 & 82,0 & 239 & 100 \\
\hline Nhómkhông ăn chay & 62 & 26,0 & 177 & 74,0 & 239 & 100 \\
\hline \multicolumn{6}{|c}{$\mathrm{OR}=1,60 ; 95 \% \mathrm{CI}: 1,03$} & $-2,47 ; \mathrm{P}=0,03$ \\
\hline
\end{tabular}


Ở nhóm phụ nữ ăn chay tỉ lệ BFP tăngchiếm 82,0\%, nhóm phụ nữ không ăn chay tỉ lệ BFP tăng chiếm $74,0 \%$ với $\mathrm{OR}=1,60 ; 95 \% \mathrm{CI}: 1,03-2,47$; sự khác biệt có ý nghĩa thống kê với $\mathrm{p}<0,05$.

Bảng 3. Phân bố tỷ lệ mỡ nội tạng

\begin{tabular}{|l|c|c|c|c|c|c|}
\hline \multirow{2}{*}{$\begin{array}{l}\text { Nhóm } \\
\text { dối tượng }\end{array}$} & \multicolumn{2}{c|}{$\begin{array}{c}\text { Bình thường } \\
(\mathbf{1 - 9})\end{array}$} & \multicolumn{2}{c|}{$\begin{array}{c}\text { Tăng } \\
(\geq \mathbf{1 0})\end{array}$} & \multicolumn{2}{c|}{ Tổng } \\
\cline { 2 - 7 } & $\mathbf{n}$ & $\mathbf{\%}$ & $\mathbf{n}$ & $\mathbf{\%}$ & $\mathbf{n}$ & \% \\
\hline Nhóm có ăn chay & 172 & 72,0 & 67 & 28,0 & 239 & 100 \\
\hline Nhómkhông ăn chay & 191 & 80,0 & 48 & 20,0 & 239 & 100 \\
\hline
\end{tabular}

Ở nhóm phụ nữ ăn chay tỉ lệ VFL tăng chiếm $28,0 \%$, nhóm phụ nữ không ăn chay tỉ lệ VFL tăng chiếm 20,0\% với $\mathrm{OR}=1,55 ; 95 \% \mathrm{CI}$ : 1,01-2,37; sự khác biệt có ý nghĩa thống kê với $\mathrm{p}<0,0$

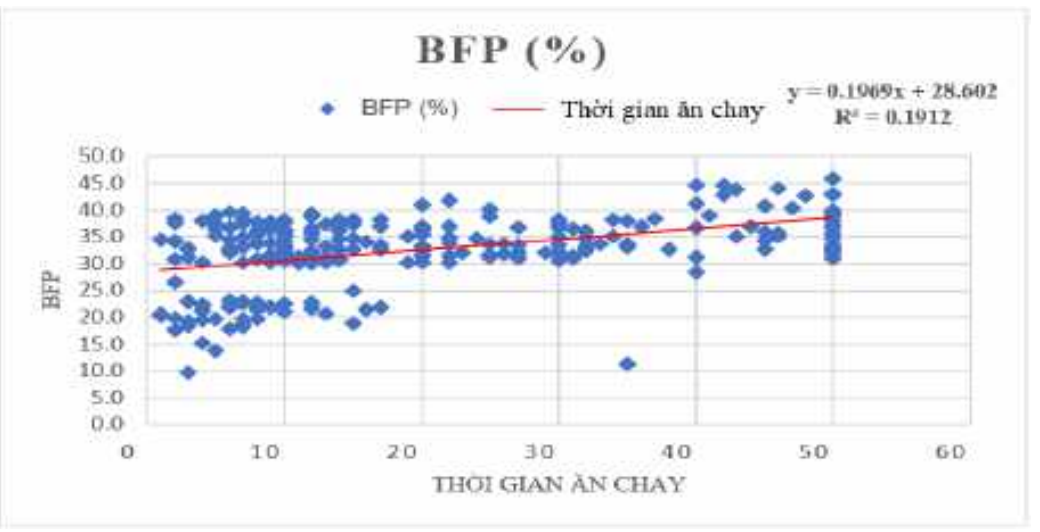

Biểu đồ 1. Tương quan giữa BFP và thời gian ăn chay

Có sự tương quan thuận trung bình giữa $\mathrm{BFP}$ với thời gian ăn chay, với phương trình hồi quy tuyến tính là $\mathrm{y}=0,1969 \mathrm{x}+28,602$ và hệ số tương quan $\mathrm{r}=0,437$; sự khác biệt có ý nghĩa thống kê với $\mathrm{p}<0,05$.

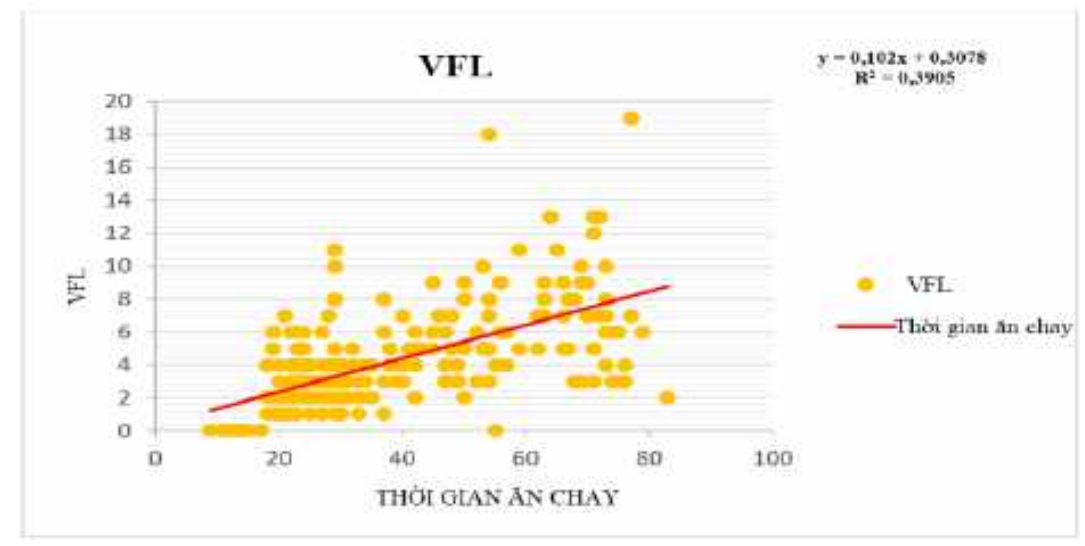

Biểu đồ 2. Tương quan giữa VFL và thời gian ăn chay

Có sự tương quan thuận trung bình giữa VFL với thời gian ăn chay, với phương trình hồi quy tuyến tính là $\mathrm{y}=0,102 \mathrm{x}+0,3078$ và hệ số tương quan $\mathrm{r}=0,625(\mathrm{p}<0,05)$. 
Bảng 4. Tương quan hồi quy đa biến giữa BFP, VFL với thời gian ăn chay

\begin{tabular}{|l|c|c|c|c|}
\hline \multicolumn{1}{|c|}{ Chỉ số } & $\mathbf{B}$ & B hiệu chỉnh & $\mathbf{n}$ & $\mathbf{p}$ \\
\hline Hằng số & $-5,664$ & & & \\
\hline BFP & 0,282 & 0,069 & 4,031 & 0,0001 \\
\hline VFL & 2,443 & 0,092 & 26,640 & $<0,0001$ \\
\hline
\end{tabular}

Qua khảo sát hồi quy đa biến số với thời gian ăn chay là biến phụ thuộc, BFP, VFL là biến độc lập có ý nghĩa thông kê, chúng tôi xây dựng phương trình hồi quy tuyến tính đa biến sau: $\mathrm{TGAC}=-5,664+0,282 * \mathrm{BFP}+2,443 * \mathrm{VFL}$.

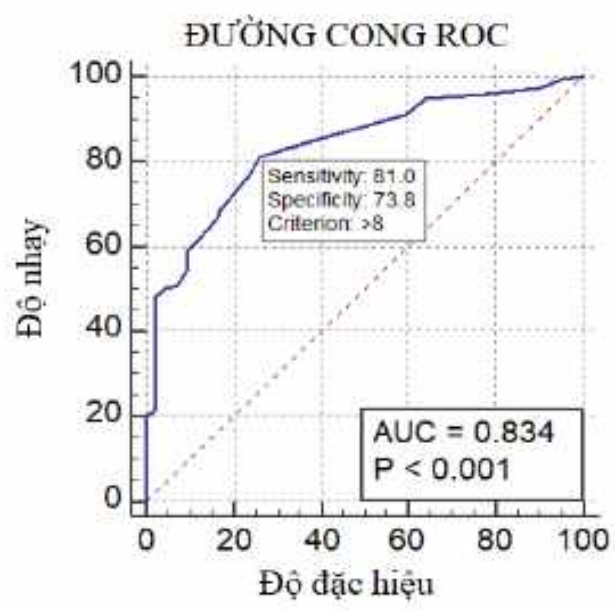

Biểu đồ 3. Biểu đồ ROC của thời gian với tăng tỷ lệ mỡ cơ thể

Thời gian ăn chay có liên quan đến việc dự đoán tăng BFP với $\mathrm{p}<0,05$ và diện tích dưới đường cong là $83,4 \%$, tại điểm cắt trên 8 năm với độ nhạy $81,0 \%$, độ đặc hiệu $73,8 \%$.

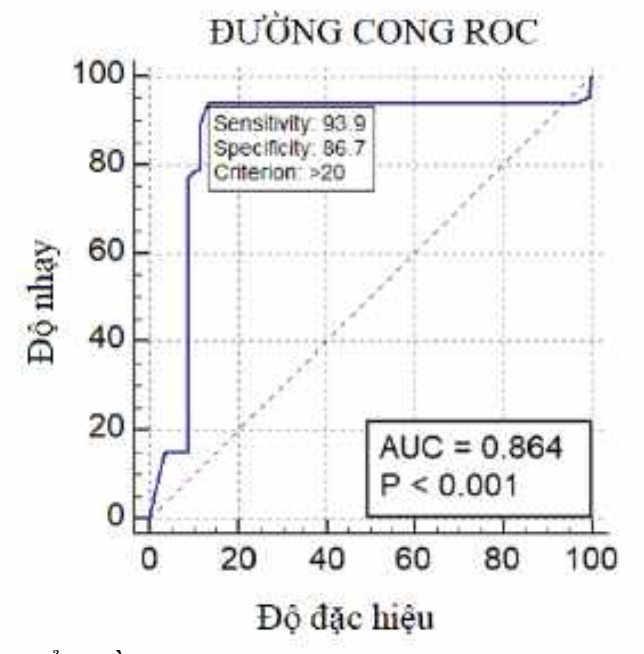

Biểu đồ 4. Biểu đồ ROC của thời gian với tăng chỉ số mỡ nội tạng

Thời gian ăn chay có liên quan đến việc dự đoán tăng VFL với $\mathrm{p}<0,05$ và diện tích dưới đường cong là $86,4 \%$, tại điểm cắt trên 20 năm với độ nhạy $93,9 \%$, độ đặc hiệu $86,7 \%$. 


\section{BÀN LUẬN}

Kết quả ở bảng 1 cho thấy ở nhóm ăn chay $B M I \geq 23 \quad \mathrm{~kg} / \mathrm{m}^{2}$ chiếm tỷ lệ $25,9 \%$ và nhóm không ăn chay $B M I \geq 23 \mathrm{~kg} / \mathrm{m}^{2}$ là $28,5 \%$. Mức huyết áp $<140 / 90$ chiếm $89,5 \%$ ở nhóm ăn chay và $80,7 \%$ ở nhóm không ăn chay. Tỷ lệ $V B \geq 80 \mathrm{~cm}$ chiếm $61,5 \%$ và $52,3 \%$ lần lượt ở 2 nhóm ăn chay và không ăn chay, nhận thấy về đặc điểm chung của nhóm ăn chay và nhóm không ăn chay sự khác biệt không có ý nghĩa thống kê p>0,05.

Qua kết quả ở bảng 2 cho thấy ở nhóm phụ nữ ăn chay tỉ lệ mỡ cơ thể tăng gấp 1,60 lần so với nhóm đối tượng không ăn chay $(\mathrm{p}<0,05)$. Kết quả nghiên cứu ở bảng 3 cũng ghi nhận được rằng ở nhóm phụ nữ ăn chay mức mỡ nội tạng tăng gấp 1,55 lần so với nhóm đối tượng không ăn chay $(p<0,05)$ nghiên cứu chúng tôi đã cho thấy ở nhóm ăn chay có nguy cơ tăng tỉ lệ mỡ cơ thể cũng như tăng mức mõ̃ nội tạng cao hơn bình thường. Vì vậy, các đối tượng ăn chay nên đi kiểm tra sức khỏe định kỳ, dự phòng các bệnh lý do tăng BFP, VFL gây ra mặc dù cũng đã có nghiên cứu cho thấy ăn chay sẽ có lợi cho sức khỏe, nhưng phải thực hiện đúng cách và không thay thế thịt bằng các sản phẩm chay giàu chất béo hoặc đã qua chế biến, điều này rất khó thực hiện.

Nghiên cứu đã ghi nhận được,tỉ lệ mỡ cơ thể BFP từ mức tăng chiếm tỷ lệ $82,0 \%$, thì thấp hơn so với nghiên cứu Lê Thị Ngọc Lan (2013) là 85,2\%, Nguyễn Ngọc Tuấn (2015) là 96,9\%[2][4]. Mức mỡ nội tạng ở mức tăng chiếm tỷ lệ $28,0 \%$ so với kết quả nghiên cứu Lê Thị Ngọc Lan là 34,3\% thì thấp hơn, nhưng kết quả của chúng tôi lại cao hơn nghiên cứu của Nguyễn Ngọc Tuấn là $21,6 \%[2]$ [4], sự khác biệt ở kết quả $\mathrm{BFP}$ và VFL của chúng tôi so với các nghiên cứu khác có thể do đối tượng chọn của các tác giả trên thực hiện trên các bệnh nhân có Hội chứng chuyển hóa $(\mathrm{n}=168)$ và Thừa cân - Béo phì $(\mathrm{n}=41)$ [2][4].

Từ kết quả của biểu đồ 1 , biểu đồ 2 cho thấy BFP tương quan thuận trung bình với thời gian ăn chay $(r=0,437 ; p<0,05)$, VFL tương quan thuận với thời gian ăn chay $(\mathrm{r}=0,625 ; \mathrm{p}<0,05)$. Một số đề tài trước đây cũng có nghiên cứu về BFP, VFLtương quan thuận với các yếu tố khác như: BMI, VB, HATT nhưng chưa có nghiên cứu nào ghi nhận mối liên quan giữa $\mathrm{BFP}, \mathrm{VFL}$ và thời gian ăn chay[2][4].Hiện nay, số người ăn chay và ăn chay trường ngày càng nhiều hơn vàchế độ ăn chay lâu năm cũng có nhiều tác dụng đối với sức khỏe. Mặc dù vậy, nhưng trong thức ăn chay trên đối tượng trường chay đã được một số tác giả đã nghiên cứu chứa một lượng lớn carbohydrate và được chế biến có nhiều chất béo vượt quá khuyến cáo đã làm gia tăng tiết insulin theo thời gian gây tân sinh mỡ[4]. Thời gian ăn chay lại tỷ lệ thuận với $B F P$ và $V F L$ có thể làm gia tăng các bệnh lý tim mạch, bệnh lý chuyển hóa và nội tiết.

Kết quả ở biểu đồ 3 và biểu đồ 4 ghi nhận nếu ăn chay trên 8 năm có dự đoán tăng BFP với độ nhạy $81,0 \%$, độ đặc hiệu $73,8 \%$ và với thời gian ăn chay $>20$ năm dự đoán tăng VFL (Se: 93,0\%, Sp: 86,7\%). Qua các nghiên cứu trước ghi nhận ăn chay trường trong thời gian dài trên 18 năm sẽ có nguy cơ tăng đường huyết và gây bệnh đái tháo đường tuy nhiên chưa chỉ ra dự báo tăng BFP với VLF ở các đối tượng ăn chay lâu năm[4].

Vì vậy, người ăn chay không nên chủ quan ăn chay thì sẽ không xảy ra các vấn đề về sức khỏe, cần phải đi kiểm tra sức khỏe thường xuyên đặc biệt là tỷ lệ mỡ cơ thể và nội tạng để phòng ngừa các bệnh lý như đái tháo đường type 2 , béo phì, rối loạn chuyển hóa,... Cần tiếp tục nghiên cứu tỷ lệ mỡ cơ thể và nội tạng ở người ăn chay trên quy mô lớn hơn.

\section{KẾT LUẦN}

- Chỉ số tỉ lệ mỡ cơ thể (BFP) có nguy cơ tăng gấp 1,60 lần; chỉ số mức mỡ nội tạng (VFL) có nguy cơ tăng gấp 1,60 lần ở phụ nữ ăn chay trườngso với nhóm không ăn chay $(\mathrm{p}<0,05)$. Nhóm ăn chay tỷ lệ BFP tăngchiếm $82,0 \%$, tỷ lệ VFL tăng chiếm $28,0 \%$.

-Có sự tương quan thuận trung bình giữa $\mathrm{BFP}$ với thời gian ăn chay với phương trình hồi quy tuyến tính $\mathrm{y}=0,1969 \mathrm{x}+28,602$; $\mathrm{r}=0,437 \quad(\mathrm{p}<0,05)$. VFL tương quan thuận 
trung bình với thời gian ăn chay phương trình hồi quy tuyến tính $\mathrm{y}=0,102 \mathrm{x}+0,3078$; $\mathrm{r}=0,625(\mathrm{p}<0,05)$. Tương quan hồi quy đa biến giữa VFL, BFP với thời gian ăn chay theo phương trình hồi quy đa biến: TGAC = $5,664+0,282 * \mathrm{BFP}+2,443 * \mathrm{VFL}$.

- Có dự đoán tăng BFP với thời gian ăn chay: Tại điểm cắt 8 năm, độ nhạy $81,0 \%$, độ đặc hiệu $73,8 \%$ và dự đoán tăng VFL với thời gian ăn chay >20 năm (Se: 93,0\%, Sp: 86,7\%).

\section{TÀI LIẸU THAM KHẢO}

1. Doãn Thị Tường Vi (2004), "Rối loạn lipid máu và tăng huyết áp ở người thừa cân", Hội nghị Khoa học toàn quốc, chuyên ngành "Nội tiết và chuyển hóa", lần thứ hai.

2. Lê Thị Ngọc Lan (2013), Nghiên cứu tỷ lệ mỡ cơ thể và mức mỡ nội tạng ở bệnh nhân có hội chứng chuyển hóa, Luận án chuyên khoa cấp II, Trường Đại học $\mathrm{Y}$ Dược Huế.

3. Nguyễn Hải Quý Trâm (2017), “Nghiên cưu giá trị dụ đoán tăng đường huyết theo thời gian ăn chay trên đối tượng nư có chế độ thuần chay", Tạp chí Y DượcTrường Đại học Y Dược Huế, tập 7, số 5tháng 11,2017, tr 58-63.

4. Nguyễn Ngọc Tuấn (2015), "Nghiên cưu chi số mõ cơ thể, mõ tạng và mõ dưới da ở bệnh nhân thì̀a cân béo phì", Luận án chuyên khóa cấp II, Trường Đại học Y Dược Huế.

5. Ashwini (2016). A comparative study of metabolic profile, anthropometric parameters among vegetarians and nonvegetarians- do vegetarian diet have a cardio protective role. International Journal of Research in Medical Sciences. 2016 Jun;4(6):2240-2245.pISSN 23206071 | eISSN 2320-6012

6. Hung SP, Chen CY (2017), “Combine body mass index and body fat percentage measures to improve the accuracy of obesity screening in young adults", Obesity Research \& Clinical Practice, vol 11, issue 1, pp 11-18.

7. Matsuzawa Y, Shimomura I, Nakamura T et al (1995), Pathophysiologyand pathogenesis of visceral fat obesity,Obes Res, 3 Suppl 2,pp.187S-194S.

8. Ru-Yi Huang, ChuanChin Huang,Frank B. Hu, (2016), Vegetarian Diets and Weight Reduction: a Meta-Analysis of Randomized Controlled Trials, JGIM, Volume 31, Issue 1, pp 109-116.

9. WHO (2000), "Obesity preventing and managing the gobal epidemic", Report of a WHO Colsultation on Obesity, series 894, pp. 174-183, 6080 . 